DOCTRINA

\title{
Constitución de 1980 y cotizaciones previsionales obligatorias
}

\author{
Constitution of 1980 and compulsory social security contributions
}

\author{
María Pía Silva Gallinato \\ Pontificia Universidad Católica de Chile
}

\begin{abstract}
RESUMEN Las cotizaciones obligatorias establecidas por ley constituyen una de las principales fuentes de financiamiento de las pensiones de seguridad social, sin que tengan el carácter de tributos. Corresponde al legislador establecer los regímenes de financiamiento de la seguridad social y determinar quién es el obligado a pagar las cotizaciones. Elevar la tasa de cotización y establecer fórmulas de financiamiento de los regímenes previsionales distintas a la actual de capitalización individual, para conformar así un sistema mixto, no se opone a lo dispuesto en el artículo 19 número 18 de la Carta y podría contribuir a legitimar nuestro sistema de seguridad social.
\end{abstract}

PALABRAS CLAVE Seguridad social, cotización obligatoria, financiamiento de regímenes de seguridad social

ABSTRACT Compulsory contributions established by law constitute one of the main sources of financing of social security pensions, without having the character of taxes. It is for the legislator to establish the social security financing schemes and determine who is obliged to pay the contributions. Raising the contribution rate and establishing financing formulas for pension systems other than the current individual capitalization, to form a mixed system, does not oppose the provisions of article 19 number 18 of the Constitution and could contribute to legitimizing our social security system

KEYWORDS Social security, compulsory contribution, financing of social security schemes 


\section{Introducción}

Bajo el lema de No más AFP (Administradoras de Fondos de Pensiones) muchos chilenos, en masivas marchas realizadas en Santiago y en diversas regiones del país, han reclamado en contra del actual sistema previsional de capitalización individual y, en especial, de la gestión que realizan las AFP. La fuerza con que han demandado reformas y la importancia que a ello se le ha asignado, ha conducido a que el actual Gobierno anunciara la presentación de un proyecto de ley sobre la materia. ¿Qué ocurrió para que ese sistema de previsión social haya comenzado a cuestionarse en Chile?

Varias explicaciones se han dado para comprender este fenómeno, entre las cuales está, por ejemplo, la desconfianza que ha generado en algunos que las AFP no solo recauden las cotizaciones previsionales y administren las cuentas de capitalización individual, sino que también ellas - constituyendo organismos de carácter privadoestén encargadas de invertir y gestionar el dinero que financiará las futuras pensiones, cobrando por ello a veces altas comisiones. ${ }^{1}$ Esto último ha ocurrido dentro de un clima generalizado de juzgamiento a la actividad empresarial, como consecuencia de haber ocurrido algunas prácticas reñidas con la moral o la legalidad, poniendo en duda la forma en que se relaciona el dinero con la política. Este fenómeno, por lo demás, ha conducido a una crisis de credibilidad no solo hacia el empresariado sino también de desconfianza hacia muchísimas otras instituciones, como son los partidos políticos, el Congreso, la Iglesia, la dirigencia del fútbol e incluso últimamente instituciones armadas como el Ejército y Carabineros.

Sin embargo, pareciera que la molestia ciudadana con relación al actual sistema previsional se origina principalmente por la percepción generalizada acerca de la insuficiencia del monto de las pensiones y, consecuentemente, de la baja en la calidad de vida que sufren las personas al jubilar, ${ }^{2}$ además de críticas acerca de su actual financiamiento.

1. Las que han ido bajando gracias a las licitaciones establecidas por la reforma de la Ley 20.255 de 2008; pero, aun así, por diversos motivos, los afiliados no optan por la más barata.

2. La Comisión Asesora Presidencial sobre el Sistema de Pensiones, en informe dado a conocer en septiembre de 2015, advirtió: que un 50\% de los pensionados entre los años 2007 y 2014, recibía pensiones iguales o inferiores a \$82.650, considerando en este monto el Aporte Previsional Solidario; que existe una brecha importante entre los montos de pensión de hombres y mujeres, por cuanto mientras la mitad de las mujeres obtiene pensiones iguales o inferiores a los $\$ 42.561$, los hombres reciben pensiones de \$112.333 o inferiores, lo cual se explica en parte por la diferencia en la edad legal de jubilación de las mujeres (6o años-quienes tienen una mayor expectativa de vida- y 65 años los hombres). Si se observa, por otra parte, la capacidad de la pensión de cumplir con el objetivo de suavizar el consumo, el 50\% de los pensionados recibe pensiones que, como máximo, equivalen al $34 \%$ de su salario promedio de los últimos diez años. Este resultado, conocido como tasa de reemplazo, también difiere significativamente entre hombres y mujeres: mientras la mitad de los hombres obtiene, bajo la definición anterior, tasas de reemplazo iguales o inferiores al 6o\%, la mitad de las mujeres recibe tasas de reemplazo que alcanzan como máximo un $31 \%$. Todo ello es sin perjuicio de que el bajo monto de 
Pues bien, para juzgar la forma en que se determinan las pensiones, se hace necesario comprender una de las principales fuentes de su financiamiento, cual es la de las cotizaciones previsionales. En tal análisis debemos recordar primero algunos conceptos previos que dicen relación con el derecho a la seguridad social.

\section{El derecho a la seguridad social}

\section{Origen de la seguridad social}

Recordemos que a fines del siglo XIX surgió la llamada Cuestión Social, que condujo a la formulación de la Doctrina Social de la Iglesia - cuya primera encíclica fue Rerum Novarum - y después, a comienzos del siglo XX, a que las Cartas Fundamentales no solo reconocieran libertades individuales, sino también derechos de carácter social y económico. Dentro de tales derechos surge el de la seguridad social, al tomarse conciencia de que no bastaba con que los trabajadores se preocuparan de establecer seguros privados - a los cuales la gran mayoría no tenía acceso por falta de liquidez económica - para solventar las dificultades económicas que les demandaría la falta de ingresos suficientes surgida con motivo de alguna contingencia social, como la vejez, enfermedad, incapacidad laboral, muerte, cesantía. Se toma conciencia de que es la sociedad en su conjunto, y el Estado en particular, los que deben adoptar las medidas tendientes a prevenir que, de ocurrir alguna de esas contingencias, se asegure a las personas el otorgamiento de prestaciones que les permita enfrentar dignamente esas situaciones de vulnerabilidad y desmedro económico.

Es así como comenzaron a crearse los primeros seguros sociales de carácter obligatorio a fines del siglo XIX en la Alemania de Bismarck. Pero es a partir del informe elaborado por William Beveridge en 1941 -que propone una reforma al sistema de seguros sociales que ya existía en Inglaterra- que se establecen las bases de la seguridad social moderna (Silva Bascuñán, 2010: 367-369).

Desde tal origen la seguridad social se fundó en algunos principios como son los de universalidad, uniformidad, integridad, suficiencia y solidaridad. Entre éstos me interesa destacar los de solidaridad y de suficiencia. Conforme al primero, cada persona debe realizar un aporte de acuerdo con su capacidad económica para que, junto con el aporte de los demás, pueda luego enfrentar los estados de necesidad que él mismo pueda sufrir. De acuerdo con el principio de suficiencia, las prestaciones deben asegurar la continuidad y mantenimiento de la capacidad de consumo del afectado por el riesgo o contingencia social (Lanata, 2015: 26-27).

las pensiones se explica también porque muchos chilenos se jubilan anticipadamente y porque existe una baja tasa de cotización, con la consiguiente insuficiencia en el ahorro y, por lo tanto, en el monto de las pensiones. 
Pues bien, en un comienzo la seguridad social se concibió como una misión amplísima del Estado dentro de su finalidad de bien común. ${ }^{3}$

Esa visión extensiva de la seguridad social la recogió la Constitución de 1925, cuando fue reformada por la Ley 17.398 de 1971, llamada también Estatuto de Garantías, al asegurar en el primer inciso del numeral 16 de su artículo 10 el derecho a la seguridad social, para luego disponer su inciso segundo:

El Estado adoptará todas las medidas que tiendan a la satisfacción de los derechos sociales, económicos y culturales necesarios para el libre desenvolvimiento de la personalidad y de la dignidad humana, para la protección integral de la colectividad y para propender a equitativa redistribución de la renta nacional. ${ }^{4}$

Ese concepto amplio de la seguridad social de alguna manera se encuentra actualmente recogido en el inciso cuarto del artículo 1 de la Constitución de 1980, que expresa que el Estado está al servicio de la persona humana y su finalidad es el bien común, para lo cual debe crear las condiciones ambientales para que todos y cada uno de los miembros de la sociedad alcancen su mayor realización material y espiritual.

\section{El derecho a la seguridad social en la Constitución de 1980}

Recogiendo un sentido más propio y restringido de la seguridad social, el artículo 19 número 18 de la Constitución actual asegura el derecho a la seguridad social precisando algunas de sus características más definitorias, ${ }^{5}$ aunque sin entregar al Estado un rol activo en el otorgamiento de las prestaciones, sino de mera supervigilancia del

3. El artículo 22 de la Declaración Universal de los Derechos Humanos expresa: «Toda persona, como miembro de la sociedad, tiene derecho a la seguridad social, y a obtener, mediante el esfuerzo nacional y la cooperación internacional, habida cuenta de la organización y los recursos de cada Estado, la satisfacción de los derechos económicos, sociales y culturales, indispensables a su dignidad y al libre desarrollo de su personalidad».

4. Los incisos que seguían de esa disposición llevaban a comprender a la seguridad social como un concepto estrechamente vinculado a la salud, desde que disponían: «La ley deberá cubrir, especialmente, los riesgos de pérdida, suspensión o disminución voluntaria como el derecho a la atención médica, preventiva, curativa y de rehabilitación en caso de accidente, enfermedad o maternidad y el derecho a prestaciones familiares a los jefes de hogares. [...] El Estado mantendrá un seguro social de accidentes para asegurar el riesgo profesional de los trabajadores. [...] Es deber del Estado velar por la salud pública y el bienestar higiénico del país. [...] Deberá destinarse cada año una cantidad de dinero suficiente para mantener un servicio nacional de salud».

5. «El derecho a la seguridad social. Las leyes que regulen el ejercicio de este derecho serán de quórum calificado. [...] La acción del Estado estará dirigida a garantizar el acceso de todos los habitantes al goce de prestaciones básicas uniformes, sea que se otorguen a través de instituciones públicas o privadas. La ley podrá establecer cotizaciones obligatorias. [...] El Estado supervigilará el adecuado ejercicio del derecho a la seguridad social». 
sistema que el legislador configure por vía de quórum calificado. Ello permite que, dentro del principio de subsidiariedad, las prestaciones puedan otorgarse por entes públicos o privados (Pica, 2012: 262).

Se trata, en efecto, como ha dicho nuestro Tribunal Constitucional, de un «servicio público» que el Estado «asume por razones técnicas, económicas y/o sociales, sin que eso impida la participación de particulares. Por lo mismo requieren de una actividad legislativa» (Tribunal Constitucional, rol 1.295-08; considerando quincuagésimo tercero). Específicamente - como dice el profesor español Miguel Sánchez Morón- son servicios de interés general no económicos, que son «aquellos en que no predomina la finalidad lucrativa sino otra de naturaleza cívica o social», poniendo ese mismo profesor, entre otros ejemplos, los servicios relacionados con los regímenes de seguridad social obligatorios (Sánchez Morón, 2013: 779).

Quienes critican el precepto han sostenido que, como al Estado solo se le confía una función de supervigilancia del sistema, la Constitución no garantiza el derecho sustantivo mismo, sino solo la posibilidad de «acceder libremente a él» (Bustos Bottai, 2016: 229-230).

Sin perjuicio de lo anterior, el constituyente de 1980 no pudo obviar que la seguridad social es un concepto rico y comprensivo de todas las medidas relacionadas con las prestaciones, en efectivo o en especie, encaminadas a garantizar una protección frente a los estados de necesidad originados por el acaecimiento de alguna de las siguientes contingencias sociales:

falta de ingresos laborales (o ingresos laborales insuficientes) debido a enfermedad, discapacidad, maternidad, accidentes de trabajo, desempleo, vejez o muerte de un miembro de la familia; falta de acceso o acceso a precios excesivos a la asistencia médica; apoyo familiar insuficiente, en particular para los hijos y adultos a cargo; pobreza generalizada y exclusión social (OIT, 2011: 9).

Lo que asegura entonces la Carta es un derecho de carácter social, que permite a las personas solicitar y, eventualmente, exigir ciertas prestaciones, servicios y programas de parte de la sociedad y del Estado a fin de lograr un mínimo de bienestar.

De acuerdo con el profesor Humberto Nogueira, el derecho a la seguridad social es:

un derecho exigible constitucionalmente por todos a tener un sistema razonable y racional de prestaciones en caso de enfermedad, invalidez, maternidad, accidente laboral, vejez o muerte y a tener un acceso en condiciones de igualdad y sin discriminación a prestaciones uniformes básicas, de acuerdo con los procedimientos y límites jurídicamente establecidos, brindado por instituciones públicas o privadas» (Nogueira, 2010: 453).

Por su parte, el Pacto Internacional de Derechos Económicos, Sociales y Culturales establece al respecto que los Estados parte «reconocen el derecho de toda persona 
a la seguridad social, incluso al seguro social». Al efecto, el Comité de Derechos Económicos, Sociales y Culturales de las Naciones Unidas ha sostenido que «la seguridad social, debido a su carácter redistributivo, desempeña un papel importante para reducir y mitigar la pobreza, prevenir la exclusión social y promover la inclusión social» (CESCR, 2007).

Ahora bien, los sistemas de seguridad social pueden ser de carácter contributivo, a través de un seguro social que asegure su financiamiento, o no contributivos, cuando es el propio Estado el que asume el costo del financiamiento a través de los impuestos que recaude (Lanata, 2015: 8).

Corresponde a los seguros sociales, por su parte, proteger a los trabajadores en caso de pérdida o disminución de sus ingresos mediante la prestación de ciertos beneficios garantizados por el Estado. El sistema de seguros es eminentemente contributivo porque se financia con aportes del trabajador, del empleador y en algunos casos del Estado; está destinado a beneficiar a la persona afiliada al sistema de previsión, aunque también su protección se extiende a las personas a su cargo, y es también de carácter obligatorio (Lanata, 2015: 15).

Pues bien, digamos además que son elementos constitutivos de los referidos seguros sociales la obligación de afiliación a un determinado régimen de previsión social; el deber de cotizar; y el derecho a las prestaciones una vez cumplidos los requisitos para que éstas sean exigibles (Lanata, 2015: 16-18).

\section{Las cotizaciones obligatorias}

\section{Las cotizaciones en la Constitución de 1980}

Siendo entonces un elemento esencial de los seguros sociales la cotización, ¿qué dice nuestra actual Constitución sobre esa materia?

El artículo 19 número 18, que asegura a todas las personas el derecho a la seguridad social, indica que «la ley podrá establecer cotizaciones obligatorias», y ello se demuestra en plenitud en los regímenes contributivos por pensiones, salud, accidentes del trabajo o enfermedades profesionales y cesantía, que se financian con cotizaciones obligatorias del trabajador y/o del empleador.

Asimismo, el número 9 del mismo artículo 19 menciona expresamente, en relación con el derecho a la protección de la salud, que la ley podrá establecer cotizaciones obligatorias.

En el estudio de la naturaleza y características que revisten las cotizaciones, conviene primero acudir a la definición que da el Diccionario de la lengua española, el cual define «cotización» como «acción y efecto de cotizar»y "cotizar», por su parte, como «pagar una cuota [...] dicho de una persona: pagar la parte correspondiente de gastos colectivos, las cuotas de la seguridad social». 
Como puede observarse de esta segunda definición, la cotización se vincula a la seguridad social, a lo previsional, correspondiendo a una cuota o porcentaje de la remuneración del trabajador o a un aporte que efectúa el empleador destinado a la seguridad social.

Ahora bien, como ya dijimos, según la Constitución de 1980, corresponde solo al legislador permitir cotizaciones de carácter obligatorio; pudiendo, por lo tanto, establecerse por otra vía cotizaciones voluntarias.

Esa obligación de cotizar - de pagar una cuota de seguridad social- dice don Alejandro Silva en su Tratado,

se explica por la necesidad de contribuir a financiar el sistema de previsión social que se establece en favor de todos los integrantes de la comunidad nacional, finalidad que no se lograría si la cotización quedara librada del todo a la sola voluntad de éstos y creando consecuentemente el riesgo de no continuar otorgando las pensiones comprometidas (Silva Bascuñán, 2010: 398).

Consecuentemente, la cotización ha sido definida por la doctrina como «una forma de descuento coactivo, ordenada por la ley con respecto a determinados grupos, afecta a garantizar prestaciones de seguridad social» (Humeres y Humeres, 1992: 479).

Como ha expresado nuestro Tribunal Constitucional, «el derecho a la seguridad social, tutelado en el artículo 19 número 18 de la Carta Fundamental, otorga un mandato especial al Estado para garantizar el acceso de todos los habitantes al goce de prestaciones básicas uniformes, sea que se otorguen a través de instituciones públicas o privadas» (Tribunal Constitucional, rol 576-06; considerando décimo tercero), acceso que se logra si se fuerza a los trabajadores y a los empleadores a contribuir a financiar, mediante cotizaciones, el sistema de seguridad social.

El mismo Tribunal sostuvo que la obligación de cotizar

es exigida por la sociedad, representada para este efecto por el órgano gestor; es una obligación de derecho público subjetivo, que faculta al titular para exigir la obligación, por lo cual nuestra jurisprudencia ha considerado que la obligación de cotizar no tiene carácter contractual ni ha nacido de la voluntad de las partes (Tribunal Constitucional, rol 767-07; considerando décimo sexto).

En relación particularmente al régimen previsional establecido en el Decreto Ley 3.50o de capitalización individual impuesto en nuestro país desde 1980, para la jurisprudencia constitucional la obligación de cotizar es

un acto mediante el cual, de manera imperativa, por mandato de la ley, el empleador debe descontar determinadas sumas de dinero, de propiedad del trabajador, para garantizar efectiva y adecuadamente prestaciones de seguridad social vinculadas a estados de necesidad que son consecuencia de la vejez y sobrevivencia, esto es, jubilaciones y montepíos (Tribunal Constitucional, rol 576-07; considerando décimo cuarto). 
Como puede observarse entonces, el establecimiento de cotizaciones obligatorias por la ley es un instrumento del que dispone el Estado para cumplir con su deber de garantizar económicamente el goce del derecho a la seguridad social (Pica, 2012: 267).

Conviene anotar además que, conforme al mismo artículo 19 número 18, las leyes que regulen el ejercicio del derecho a la seguridad social son de quórum calificado (mayoría de los diputados y senadores en ejercicio); por lo tanto, las que establezcan cotizaciones obligatorias también deben tener ese rango. La legalidad de las cotizaciones previsionales se afirma, asimismo, desde que entre las materias de ley que establece taxativamente el artículo 63 de la Carta de 1980, se encuentran: «Las materias básicas relativas al régimen previsional y de seguridad social» (número 4), siendo tal materia de iniciativa exclusiva del Presidente de la República.

\section{Naturaleza jurídica de las cotizaciones obligatorias}

La cotización obligatoria es considerada por algunos como una exacción parafiscal, en tanto, para otros, constituiría un tributo de derecho público. ${ }^{6}$

De lo que no hay dudas es que la cotización reúne las características de ser autónoma; tener una destinación específica, por cuanto se encuentra afecta a uno o más regímenes previsionales; se halla, en fin, establecida por la sociedad imperativamente a los sujetos obligados al pago (empleadores y/o trabajadores) para solventar total o parcialmente el costo de una prestación de interés social (Cifuentes y Silva, 2017: 39).

En efecto, las cotizaciones, y en general todos los recursos de seguridad social, son de destinación específica e inmodificable. Se dirigen y utilizan solo para fines de seguridad social, constituyendo, por lo tanto, para el trabajador un derecho irrenunciable y público de carácter obligatorio.

Los tributos, por su parte, de acuerdo con lo que ha dicho el Tribunal Constitucional son

prestaciones pecuniarias exigidas coactivamente por la ley a quienes incurran en los hechos o situaciones que ésta grava, con miras a subvenir al funcionamiento del Estado en su conjunto, sin que vayan acompañadas de una contraprestación directa y específica en beneficio del contribuyente (Tribunal Constitucional, rol 1.405-09; considerando décimo).

Esta concepción se ajusta, por lo demás, a lo que establece el inciso tercero del numeral 20 del artículo 19, cuando señala que los tributos «ingresan al patrimonio de la Nación y no podrán estar afectos a un destino determinado».

De tal definición no puede concluirse que las cotizaciones se asimilen a un tributo, por cuanto si bien comparten con éste constituir prestaciones pecuniarias exigidas

6. Humeres y Humeres (1992: 479-481) sostienen esta última posición. 
coactivamente por la ley a quienes incurran en las situaciones que ésta grava —en el caso a los trabajadores dependientes que están obligados a cotizar con miras a recibir una futura pensión o a sus empleadores-, no poseen las demás características propias del tributo.

En efecto, las cotizaciones previsionales no son recaudadas por el Estado ni ingresan a las arcas fiscales, sino que generalmente a entes privados que los administran, y además están destinadas a un fin determinado: buscan que, de surgir el estado de necesidad que prevé el ordenamiento jurídico, colaboren a financiar una pensión u otro tipo de prestación social y no se encuentran, por lo tanto, afectas a un destino relacionado con el servicio público. Tienen, por lo tanto, el carácter propio que les da la propia Constitución al definirlas y denominarlas en forma separada a los tributos.

Ahora bien, aunque las cotizaciones son exigidas para satisfacer una necesidad social, ello no obsta a que el servicio público de seguridad social pueda prestarse en colaboración con particulares - a través de organismos estatales o privados-, con toda la connotación social -y, por cierto, jurídica- que ello reviste. Es decir, las cotizaciones pueden ingresar a un ente de carácter privado que administre los fondos reunidos - cobrando para ello una comisión - a fin de lograr su mayor rentabilidad, como lo hacen en nuestro país las Administradoras de Fondos de Pensiones (AFP). Ello es consecuencia - como ya advertimos- de la aplicación del principio de subsidiariedad que consagra nuestra Constitución. En todo caso, cualquiera sea el sistema que se adopte, el Estado está obligado a controlar su debido funcionamiento, en virtud de que la Carta así lo dispone.

\section{Fuentes de financiamiento de la seguridad social}

Tradicionalmente se distingue entre los regímenes financieros de reparto y de capitalización. Recordemos que el de reparto - como sostienen los profesores Hugo Cifuentes, Pablo Arellano y Francisco Walker- se basa en un equilibrio entre la población activa, que cotiza, y la población pasiva, que recibe las prestaciones y se depositan en un fondo común. Tal sistema se funda en el principio de solidaridad intergeneracional, por ser la población activa quien principalmente financia las prestaciones de los jubilados o de los sectores pasivos, en términos amplios (Cifuentes, Arellano y Walker, 2013: 106). Mientras tanto, en el de capitalización, cada generación constituye los fondos o ahorros necesarios para atender las contingencias sociales que le afecte (Cifuentes, Arellano y Walker, 2013: 108).

Desde que se dictara el Decreto Ley 3.50o de 1980, Chile optó por un régimen de capitalización individual para el financiamiento de los riesgos derivados de la vejez, sobrevivencia e invalidez, a cargo de las AFP y, desde la dictación de la Ley 19.728 de 2001, asumió el riesgo del desempleo a través del seguro de cesantía. La cuenta individual es uno de los mecanismos que contempla este último seguro, la que adi- 
cionalmente incluye un fondo solidario constituido con recursos o aportes fiscales más la cotización del empleador, destinado a generar prestaciones para quienes no tienen derecho a girar de la cuenta individual o, de tenerlo, han consumido el saldo y les sigue correspondiendo acceder a beneficios.

Por lo explicado, en el régimen de capitalización individual la capacidad de ahorro se convierte en un factor decisivo para la determinación de las prestaciones para cubrir los riesgos antes dichos.

Ese sistema, sin embargo, convive con otros, como son algunos de los antiguos regímenes de reparto que existían antes de la reforma de 1980 y que se han mantenido en relación con la regulación de las pensiones que administra actualmente el Instituto de Seguridad Previsional y también al sistema que gestionan las Cajas de Previsión de la Defensa Nacional y de la Dirección de Previsión de Carabineros.

También se creó, mediante la Ley 20.255 de 2008, un sistema de pensiones -complementario al de vejez e invalidez contenido en el Decreto Ley 3.500- a través del cual el Estado otorga una pensión mínima (llamada solidaria) a los integrantes de una familia que pertenezca al $60 \%$ más pobre del país, a quienes nunca cotizaron en un régimen previsional o cotizaron muy poco - situación esta última en que no les corresponde una pensión básica solidaria sino un aporte previsional solidario si reúnen todos los demás requisitos- y cuyo sistema de pensiones es administrado también por el Instituto de Previsión Social.

Ahora bien, volviendo al tema de las cotizaciones, recordemos que según nuestro Tribunal Constitucional, dentro del régimen de capitalización individual que administran las AFP, debe diferenciar entre lo que usualmente se denomina cotización previsional y el fondo previsional.

El fondo previsional se forma, de acuerdo con lo que dispone el Decreto Ley 3.50o, como un patrimonio independiente y diverso del patrimonio de la Administradora, sin que ésta tenga dominio sobre los dineros depositados en él. Cada Fondo de Pensiones está constituido principalmente por las cotizaciones y demás dineros depositados en la cuenta de capitalización individual, por lo cual la propiedad del trabajador sobre dicho «fondo previsional» nace cuando los dineros son depositados en dicha cuenta de capitalización individual; en cambio, sobre las cotizaciones previsionales el trabajador tiene el derecho a exigir al empleador el cumplimiento del deber que tiene de retenerlas, declararlas y depositarlas en dicho fondo o en el de cualquier otro organismo previsional que establezca la ley (Tribunal Constitucional, rol 767-07; considerando décimo tercero).

No hay duda de que la propiedad que tiene el afiliado a una AFP sobre los fondos previsionales que conforman su cuenta individual, aunque presenta características especiales, se encuentra plenamente protegida por el artículo 19 número 24 de la Constitución Política de la República, que reconoce el derecho de propiedad no 
solo sobre los bienes corporales, sino también respecto de los incorporales (Tribunal Constitucional, rol 334-01; considerando quinto).?

En todo caso, respecto de los fondos acumulados en las cuentas individuales que administran las AFP conviene destacar que su titular tiene un dominio sui generis.

En efecto, dicha propiedad se encuentra sujeta a un modo, por cuanto solo se podrá acceder a tales fondos en tanto el afiliado al sistema cumpla con los requisitos que establezca la ley relacionados con la verificación a su respecto de una contingencia social (vejez, invalidez o muerte del jefe de hogar), la cual genera un estado de necesidad, que corresponde a la falta de los ingresos que obtenía de forma previa a la ocurrencia de la contingencia.

Por otra parte, la cotización empresarial prácticamente no existe en nuestro sistema jurídico, ya que, en gran parte de los regímenes previsionales, el mayor aportante es el trabajador afiliado. ${ }^{8}$

Para algunos la cotización empresarial no es un ingreso directo para el trabajador en representación del cual se efectúa, salvo que el legislador le otorgue esa característica, como ocurre en nuestro ordenamiento jurídico. Así, por ejemplo, la cotización adicional que se destina al financiamiento de la AFP, incluido el pago de la prima del seguro de invalidez y sobrevivencia que la AFP debe contratar en una compañía de seguros previa licitación para cada uno de sus afiliados, se financia con la cotización del empleador en caso de los trabajadores dependientes. ${ }^{9}$

La cotización como exacción parafiscal, además, no necesariamente constituye una reserva individual para financiar la prestación para una persona determinada (del trabajador que la efectúa o en nombre de quien se efectúa), sino que es el legislador quien puede darle o no esa particular titularidad (Cifuentes y Silva, 2017: 39).

En el caso de la cotización empresarial, ésta constituye un aporte que, basado en norma constitucional, es exigido por el legislador de quórum calificado con el exclusivo objeto de contribuir a financiar, en conjunto con el trabajador o en exclusiva, las prestaciones de seguridad social, salvo que aquel le dé un destino de reserva estrictamente individual.

Entonces, conforme a la regla constitucional que expresa que se podrán establecer

7. Como señala Larraín (2012): «De este dominio, aun cuando se encuentra afecto a un fin específico y sujeto a una serie de condiciones legales para ejercer su derecho a pensionarse, es que nacen una serie de derechos para el afiliado, entre los cuales se cuenta el de transferir sus fondos a otra Administradora, el de elegir el nivel de riesgo que quiere asumir, el de decidir si quiere efectuar aportes voluntarios en forma individual o colectiva etcétera».

8. Excepcionalmente el Decreto Ley 3.500 establece la cotización del empleador en relación con los trabajos pesados o penosos (artículo 17 bis), y la Ley 16.744 la dispone en relación con los riesgos del trabajo y el seguro de cesantía. Por su parte, el trabajador dependiente cotiza obligatoriamente para pensiones, salud y cesantía, cuando en este último caso son trabajadores con contrato indefinido.

9. Artículo 17 del Decreto Ley 3.500. 
cotizaciones obligatorias, éstas constituyen, más que ahorros forzosos de quien las hace - para sí o por sus trabajadores- prestaciones pecuniarias destinadas a cubrir los requerimientos que surjan con motivo de ocurrir un estado de necesidad.

Por otra parte, nuestra Constitución no detalla quiénes deben pagar las cotizaciones, siendo el legislador el que debe establecer quién es el obligado.

\section{Constitucionalidad de algunos cambios para obtener mejores pensiones}

Para satisfacer en parte la demanda por un régimen que otorgue mejores pensiones y prestaciones sociales que el actual, como reclama la ciudadanía, nada obsta a destinar un nuevo porcentaje de las cotizaciones a un fondo común para pensiones dentro de un régimen de reparto que sea financiado con una cotización a cargo del empleador.

En efecto, ello no implicaría un tributo porque tendría un destino inespecífico, ni tampoco constituye un atentado a la propiedad sui generis de las cuentas de capitalización individual que manejan actualmente las AFP, porque tal derecho solo se adquiere respecto de las cotizaciones destinadas a dichas cuentas, y que ya ingresaron a ellas.

Destinar entonces las cotizaciones previsionales a un fondo común buscaría satisfacer la necesidad de que los regímenes de seguridad social se basen no solo en la universalidad, integridad y unidad, sino que también en el principio de solidaridad, que busca que toda la comunidad realice un esfuerzo para contribuir a la seguridad social, especialmente en auxilio de quienes estén en una postura social más desfavorable (Silva Bascuñán, 2010: 382). Se trataría en definitiva de que los partícipes del sistema se comprometan - empleador y trabajador - a buscar satisfacer las necesidades de las futuras generaciones o de los actuales pensionados.

$\mathrm{Al}$ respecto, nuestro Tribunal Constitucional ha afirmado que la supresión, en el texto del artículo 19 número 18 de la Constitución, de los principios rectores de la seguridad social —entre los cuales se encuentra el de solidaridad- «carece de relevancia, pues tales principios configuran la esencia de aquel derecho, de modo que se entienden siempre absorbidos por él, ya que de lo contrario perdería su identidad específica» (Tribunal Constitucional, rol 1.287-09; considerandos 25 a 31), expresando en otro fallo, que

el contenido esencial de la seguridad social se revela en una interpretación sistemática del texto constitucional en el que se recogieron los principios de solidaridad, universalidad, igualdad y suficiencia, y unidad o uniformidad, sobre todo si se ven conjuntamente el derecho a la salud (artículo 19 número 9) y el derecho a la seguridad social (artículo 19 número 18). Así, en primer lugar, el principio de solidaridad se expresa en el deber que tiene el Estado, es decir, la comunidad políticamente organizada, de garantizar económicamente estos derechos. Las expresiones de la Constitución son claras en este sentido, toda vez que se obliga al Estado a «garantizar» el 
goce de los derechos; asimismo, se faculta al legislador para establecer cotizaciones obligatorias (numerales 9 y 18 del artículo 19 de la Constitución). (Tribunal Constitucional, rol 1710-10; considerando centésimo trigésimo primero).

El principio de solidaridad, por lo demás, se ve reflejado también en que actualmente existen en nuestro ordenamiento jurídico algunas prestaciones de seguridad social que se fundan también en ese postulado.

Es así como, por ejemplo, el seguro de la Ley 16.744 sobre Accidentes del Trabajo y Enfermedades Profesionales se financia con aportes del empleador y se destina a un fondo común y solidario que beneficia a todos los trabajadores afiliados a la entidad previsional, ya sea actuales o futuros; el $7 \%$ de la remuneración que los trabajadores aportan a Fonasa sigue también un criterio de solidaridad entre los cotizantes de la misma y las sucesivas generaciones; y, en fin, el seguro de cesantía se refleja en una cuenta individual por trabajador, pero contempla un fondo solidario que considera el aporte del empleador más aportes fiscales determinados.

Por último, junto a las prestaciones contributivas a las que nos estamos refiriendo (seguros sociales), existen asimismo prestaciones complementarias a ellas o autónomas (pensiones solidarias, asignaciones familiares, subsidios maternales y paternales, etcétera), que son financiadas con impuestos generales. Esos regímenes, cada día más difundidos a nivel comparado, confluyen con los regímenes previsionales de financiamiento bipartito, en los que la cotización no está destinada a un titular específico, sino a la generalidad de los afiliados trabajadores dependientes (en el caso de la cotización empresarial), y ello es reflejo de la solidaridad intra e intergeneracional, que es manifestación del ya mencionado principio de la solidaridad.

Por lo tanto, no existe impedimento alguno para imponer, por ejemplo, una cotización a cargo del empleador que corresponda a una tasa adicional, por ejemplo, ascendente al $5 \%$ de la remuneración, que sea destinada al financiamiento de las pensiones y tenga una forma de gestión diferente a la que actualmente existe para el 10\% del aporte que ahora realiza el trabajador y cuyos fondos acumulados corresponde administrar a las AFP.

Nada obsta además a que esa nueva tasa sea recaudada y administrada por un ente diferente a las actuales administradoras de fondos de pensiones - como podría ser un cuerpo colegiado y autónomo-, siempre, por cierto, que ello esté determinado por una ley de quórum calificado y que se asegure que tal organismo cumpla con altas exigencias técnicas para asegurar la correcta administración de los fondos recaudados.

La nueva cotización adicional a la ya existente - en forma completa o solo una parte de ella- podría también perfectamente ingresar a un fondo común y solidario para permitir mejorar las pensiones, cumpliendo así también con el principio de la seguridad social llamado de suficiencia, que persigue que los regímenes previsionales 
cubran en la forma más amplia la respectiva contingencia social, de manera tal que no se afecte gravemente la capacidad de consumo. De este modo se podría cumplir con lo señalado por la Comisión de Derechos Económicos, Sociales y Culturales de las Naciones Unidas, en cuanto a que las prestaciones de cualquier sistema de seguridad social

deben ser suficientes en importe y duración a fin de que todos puedan gozar de sus derechos a la protección y asistencia familiar, de unas condiciones de vida adecuadas y de acceso suficiente a la atención de salud. Para lograr esto, los Estados deben revisar periódicamente los criterios empleados para determinar el nivel suficiente. Cuando una persona cotiza a un plan de seguridad social que ofrece prestaciones para suplir la falta de ingresos, debe haber una relación razonable entre los ingresos, las cotizaciones abonadas y la cuantía de la prestación pertinente (CESCR, 2007: 8).

\section{Conclusiones}

Las cotizaciones obligatorias establecidas por ley, según lo que dispone el artículo 19 número 18 de la actual Carta Fundamental, constituyen una de las principales fuentes de financiamiento de las pensiones de seguridad social, sin que tengan el carácter de tributos, por cuanto si bien son prestaciones pecuniarias exigidas forzosamente, a diferencia de estas últimas, tienen una destinación específica y no ingresan a arcas fiscales.

La Constitución entrega al legislador el establecimiento de distintos regímenes de financiamiento de la seguridad social, los que han de basarse en los diferentes principios que la conforman, como son los de suficiencia y solidaridad.

Asimismo, las cotizaciones obligatorias pueden ser no solo de cargo del trabajador, sino que también del empleador, desde que nuestra Constitución no detalla quiénes deben pagar las cotizaciones, correspondiendo al legislador determinar quién es el obligado.

El establecimiento de nuevas fórmulas de financiamiento de los regímenes previsionales distintas a la actual de capitalización individual que administran las AFP, con miras a otorgar mejores pensiones u otras prestaciones sociales a través de elevar la tasa de cotización, podría legitimar nuestra institucionalidad previsional. Ello supondría, por una parte, no afectar el derecho de propiedad que tienen los imponentes sobre los fondos previsionales depositados en sus cuentas individuales administradas por las AFP y, por otra, complementar tal sistema con alguno que impulsara también la solidaridad y suficiencia, conformando así un sistema mixto, lo cual, por lo ya dicho, en ningún caso se opone a lo dispuesto en el artículo 19 número 18 de la Carta, que asegura el derecho a la seguridad social. 


\section{Referencias}

Bustos BotтaI, Guillermo (2016). «Nueva Constitución y derechos sociales: hacia un nuevo paradigma». En E. Chia y F. Quezada, Propuestas para una nueva Constitución (originada en democracia). Santiago: Instituto Igualdad.

CESCR, Comité de Derechos Económicos, Sociales y Culturales de las Naciones Unidas (2007). Observación general núm. 19. Disponible en http://bit.ly/2keGfG4.

Cifuentes Lillo, Hugo y María Pía Silva Gallinato (2017). «Constitución y cotizaciones previsionales». En La Tercera, sábado 15 de abril de 2017, Negocios, p. 39.

Cifuentes Lillo, Hugo, Pablo Arellano Ortiz y Francisco Walker Errázuriz (2013). Seguridad Social. Parte general y pensiones. Santiago: Librotecnia.

Comisión Asesora Presidencial sobre el Sistema de Pensiones (2015). Informe Final. Disponible en http://bit.ly/2kJQXn9.

Humeres Magnan, Héctor y Héctor Humeres Noguer (1992). Derecho del Trabajo $y$ de la Seguridad Social. 13. ${ }^{a}$ edición. Santiago: Jurídica.

LARRAÍn VilLanUeVA, Florencia (2012). «El sistema privado de pensiones en Chile y sus resguardos constitucionales». Revista Chilena de Derecho (Pontificia Universidad Católica de Chile), 39 (2): 541-551.

Lanata Fernández, Gabriela (2015). Manual de Legislación Previsional. 2. ${ }^{a}$ edición. Santiago: Thomson Reuters.

Nogueira Alcalá, Humberto (2010). Derechos fundamentales y garantías constitucionales. Tomo 3. 1. ${ }^{\mathrm{a}}$ reimpresión. Santiago: Librotecnia.

Pica Flores, Rodrigo (2012). «El derecho a la seguridad social en el sistema constitucional chileno». En G. Aguilar Cavallo, Derechos económicos, sociales y culturales en el orden constitucional chileno. Santiago: Librotecnia.

SÁnchez Morón, Miguel (2013). Derecho Administrativo. Parte general. 9. ${ }^{a}$ edición. Madrid: Tecnos.

Silva Bascuñán, Alejandro (2010). Tratado de Derecho Constitucional. Tomo XIII. Santiago: Jurídica.

\section{Sobre la autora}

María Pía Silva Gallinato es abogada y magíster de la Pontificia Universidad Católica de Chile. Profesora de Derecho Constitucional de la Pontificia Universidad Católica de Chile y Universidad Alberto Hurtado.Su correo electrónico es mpiasilvag@ gmail.com. 
La Revista de Derecho Público es publicada, desde 1963, dos veces al año por el Departamento de Derecho Público de la Facultad de Derecho de la Universidad de Chile. Su propósito es la difusión de los avances del derecho público nacional e internacional y la socialización de artículos de investigación inéditos tanto de la comunidad académicas nacional e internacional.

DIRECTORA

Ana María García Barzelatto

SECRETARIO DE REDACCIÓN

Felipe Peroti Díaz

(fperoti@derecho.uchile.cl)

SITIO WEB

revistaderechopublico.uchile.cl

CORREO ELECTRÓNICO

publico@derecho.uchile.cl

LICENCIA DE ESTE ARTÍCULO

Creative Commons Atribución Compartir Igual 4.0 Internacional

La edición de textos, el diseño editorial

y la conversión a formatos electrónicos de este artículo

estuvieron a cargo de Tipográfica

(www.tipografica.cl). 